Original scientific paper

\title{
Creation and Use of Game-Based Learning Material
}

\author{
Josip Mihaljević \\ School for nurses Vrapče \\ Bolnička cesta 32, Zagreb, Croatia \\ jomix@gmail.com
}

\begin{abstract}
Summary
Rising popularity of games and increased use of technology in schools have made game-based learning more popular in education. In this paper the advantages of game-based learning are analyzed and some research results on the effect of game-based learning are given. A pilot research on the use of educational games for motivating students was conducted on high school students and results are given. The paper also presents the author's websites which contain many custom educational games such as Tic-tac-toe, Snake, Tetris, Memory, Hangman, etc. These games were created free of charge and without any copyright restrictions using certain web services and available game codes from different websites. A number of crated games are played like traditional games they are based on but have educational content integrated into game mechanics, such as a question for every turn in the game. A number of games were created as a fun way to help students learn languages (Croatian, German, Latin) as well as the basic facts of Computer Science (recognizing parts of a computer). There are also archival games which were created in a similar way as museum games to promote archives and archivist's activities where a player can match pictures of archives to get basic information about them or solve puzzles containing the pictures of archival holdings.
\end{abstract}

Key words: education, free software, game creation, game-based learning, gamification, multimedia, motivation of students, websites

\section{Introduction}

Games are often considered as a media that combines other media such as text, sound, and picture. Their strength lies in their interactivity as players can interact with the previously mentioned media. Thus, it may seem that games are perfect for studying but the problem is that games aim at having fun so they are mostly used in entertainment industry rather than education. However, that does not mean that there is no place for games in education. Traditional teaching methods are slowly being modernized and adapted to specific needs of the information driven society primarily through various attempts to integrate computers and multimedia in the everyday classroom (Mitrović \& Seljan 2008: 
248). Due to their interactivity, games can, even more than movies, be used as a way of motivating students for certain subjects. Educational games can improve the outcome of learning if designed and used correctly in class (Gros 2007: 3136). As console and PC games are too expensive to produce and distribute, the focus should be on smaller mobile or web games. Web games have evolved and now with the new HTML5 language for their creation, they can be played on devices with different screen sizes and different web browsers without installing additional software (Gasston 2013: 21). They are also much easier to make with various types of free technologies and codes available on the Internet and they can be distributed through hyperlinks.

\section{Difference between Gamification and Game-Based Learning}

The idea of gamification is to add game-elements to a non-game situation. Corporate reward programs are a good example of gamification. They reward users with badges and points for certain behavior they favor. These points can later be used to get items from the store for free or for a lower price. This is very similar to RPG (Role-playing game) where a player gets points during gameplay which he can spend on getting game items (Trybus 2009). In the classroom, gamification has been integrated in a more authentic manner as some classrooms have become a living, breathing game. The example of gamification in classroom is when the teacher displays students' points and rankings on the board. In this way, the students can see their progress and compare it with the progress of other students and be more motivated to improve themselves. Another example of gamification can be seen with certain plugins for Moodle which give each profile badges and achievements for passing exams or certain subjects (Hall 2015).

Game-based learning, as compared to gamification, actually uses video games as a medium for learning. There are games that are specifically designed for learning, like My Coach series of video games for Nintendo DS console which are used for learning foreign (e.g. French and Chinese) languages by solving different puzzles (Spencer 2007). Although games as Assassin's Creed and Total War Series were not designed for educational purposes they can also be used for learning history because they realistically depict the time period in which the story of the game takes place (Higgins 2017). Game-based learning is not so often used as gamification in a classroom situation and cannot replace traditional learning. However, games can be used as a good medium for motivating students for certain subjects and games with questions and assignments can be used for repeating what the students have learned. This is why there should be more games made for educational purposes especially now when technology has become more accessible, much easier to use and there are many open source free programs and software which can be used for efficient game creation (Ally \& Samaka 2013: 1-2). 
It has been proved that students generally enjoy working with computers, and this fact should be used to motivate them during learning process (Dovedan, Seljan \& Vučković 2002: 73). Numerous studies support the view that games have a positive effect on learning. A growing number of researchers are committed to developing educational games for promoting student skills. One of the popular game learning platforms well known in Croatia is Kahoot, in which teachers can create quizzes for their students which they can access with their passwords. However, little is as yet known of how games can influence student acquisition of learning and innovation skills. Meihua Qian and Karen R. Clark (2016) conducted a research using the Academic Search Complete Database ${ }^{1}$. They analyzed 137 studies on game-based learning. Their research shows that the influence of games on the success of learning is mostly dependent on the way they combine educational content with certain game mechanics which are successful in the entertainment game industry as well. They think that specifically designed games for learning different subjects and aiming at different groups defined by age and gender mostly work better than typical commercial and educational games. The problem is how to develop specific games for specific groups of students because that requires programming and finding or creating appropriate graphical resources. Another problem that Clark and Qian stressed in their research is that there are some indications that there is as yet not enough evidence that game-based learning improves the learning process. While the majority of the results were statistically significant, the practical significance of many of the empirical findings remains unknown.

Other researchers think that games may stimulate information acquisition, enhance the ability to think quickly and analyze different situations as well as help with aspects of coordination and concentration on visual details (Anderson \& Lawton 2009; Garris, Ahlers \& Driskell 2002; Wilson et al. 2009). However, there are also disadvantages such as children being overstimulated by games (Barlett et al. 2009; Thomas, Gentile \& Anderson 2008). Games may also be irrelevant to the content of the subject taught or linked to excessive or addictive play (McFarlane et al. 2002; Prensky 2001). Unfortunately, many researchers analyze only negative effects of violent videogames but really focus on the positive aspect that games can have on developing psychomotoric skills or how game mechanics can be used for learning purposes (Bilić, Gjukić \& Kirinić 2010: 200-203).

\footnotetext{
${ }^{1}$ A comprehensive full-text database for multidisciplinary research designed for academic institutions. This database is a leading resource for scholarly research. It supports high-level research in the key areas of academic study by providing journals, periodicals, reports, books and more (EBSCO 2012).
} 
INFuture2017: Integrating ICT in Society

\section{Creation of Educational Websites}

Three websites for different game contents where created: Language Games and Multimedia Display of Language, Computer Games and Other Multimedia Content, and Archival Games.

\section{Language Games and Multimedia Display of Language}

The undeniable advancements in technologies used for educational purposes have, in many ways, improved the traditional language teaching methods. Teachers can more easily find teaching materials and have access to various online multimedia sources which make it possible to improve the, sometimes dull, course materials (Mitrović \& Seljan 2008: 251).

The website Language Games and Multimedia Display of Language ${ }^{2}$ was created for the purpose of presenting and distributing language games for different languages. Language games are seen as a fun way of learning different languages and learning facts about language and literature. The idea to create this website came after the games for learning Glagolitic letters were made for The Old Church Slavonic Institute ${ }^{3}$ and memory and spelling games were made for the Institute of Croatian Language and Linguistics ${ }^{4}$. The first web domain for the site was http://www.jezicneigre.tk which was hosted on free web hosting service 000 webhost. After that, the site was transferred to a new web host and got a new domain http://www.jezicneigre.com. The old .tk domain is still active but it automatically redirects visitors to the .com site. The websites were created by using Wordpress CMS system. This site not only includes typical language games, e.g. quizzes that most language learning sites such as Duolinguo and Memrise use but present many other non-typical language games as well. The games on this site are based on popular games that are familiar to all generations such as Memory, crossword puzzles, Snake, Hangman, Word Search, Tic-Tac-Toe, and Tetris. There are also some games that are inspired by modern games such as Flappy Glagolitic which was based on the popular game Flappy Bird designed in 2013 for mobile devices (Williams 2014) and Glagoljatrix which was based on the FPS (first person shooter) game SUPERHOT made in 2016 for PC and new generation consoles such as Xbox ONE (Orland 2016).

\footnotetext{
${ }^{2}$ Language Games and Multimedia Display of Language. 2016. http://www.jezicneigre.com (2.4.2017)

${ }^{3}$ Glagolitic games. 2017. https://zci.stin.hr/hr/article/112/osmosmjerka_s_glagoljicom (2.4.2017)

${ }^{4}$ Croatian language in games. 2017. http://hrvatski.hr/igre/ (2.4.2017)
} 


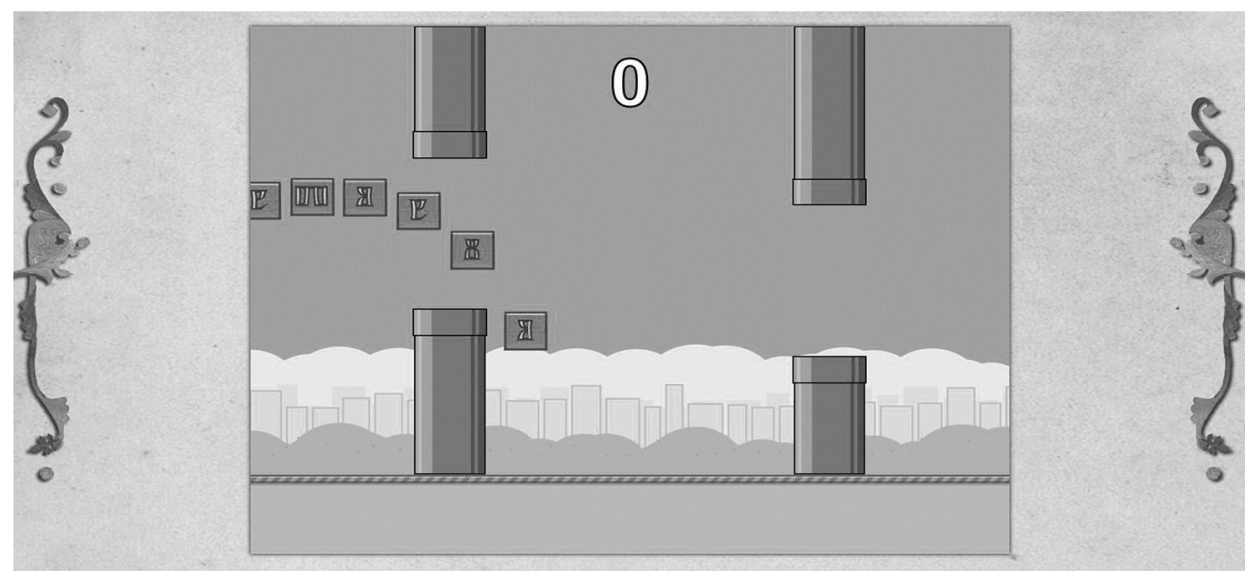

Figure 1. Flappy Glagolitic - a game inspired by Flappy Bird which can be used for learning Glagolitic letters

The reason for adding multimedia display of language in the title of the website is not to exclude content such as interactive maps or timelines, e.g. the timeline presenting the history of Croatian dictionaries ${ }^{5}$. Some games for learning German were made in collaboration with a student of German.

The design, including the games, is web responsive, so games can be played on mobile devices. The games are divided into categories based on the language and each game has multiple tags (key words) which connect games having similar content and games of the same type. A Facebook page for the site was created and is used for promoting games as at present everything is spread through social media ${ }^{6}$. The site post for games has icons for sharing games through different social networks such as Facebook, Twitter, LinkedIn, and Pintrest. The site has no commercials, all of the games are free and it does not require registration. Many of the games were transferred to the new site Croatian in School ${ }^{7}$ of the Institute of Croatian Language and Linguistics. On this website a special section is dedicated to language games and quizzes. Language games for learning German are also featured as a link among teaching materials on the website of the School for nurses Vrapče.

\footnotetext{
${ }^{5}$ Croatian dictionary history timeline. 2016. http://jezicneigre.com/hr/povijest-rjecnika/ (2.4.2017)

${ }^{6}$ Language games and multimedia display of language - Facebook page. 2017. https://www. facebook.com/jezicne/ (2.4.2017)

${ }^{7}$ Croatian in School. 2017. http://hrvatski.hr/ (2.4.2017)
} 
INFuture2017: Integrating ICT in Society

\section{Computer Games and Other Multimedia Content}

Similar site for learning Computer Science in school ${ }^{8}$ was created. On this site students can play games for learning programming language generations, computer components, and other computer related topics.

This site was created for high school students who have Computer Science in their freshman and sophomore years. This site has a design similar to the site analyzed above. The games are divided into categories and have tags. Most of the games, e.g. quizzes, crossword puzzles, memory games and tic-tac-toe games are similar to the games on the site mentioned above but their graphical design if different and looks more computer-like. The content for students is being made based on the data that they are studying with their teacher. The most popular game on this site is Binary Tetris. It consists of two columns, one is for placing Tetris blocks and the other switches binary digits from 0 to $\mathbf{1}$ and vice versa depending on the position of the blocks. This game also uses a font that looks very 8-bit arcade like. Every time a player completes a row, the game pauses and a multiple choice question appears on the screen which the player has to answer to continue the game. If a player answers correctly, the game continues at normal speed and offers the player an extra point but if the answer is incorrect, the player loses a certain number of points and the game speeds up, which makes playing harder. The games on this site also have buttons which allow them to be shared on social networks but currently there is no official social website for these games.

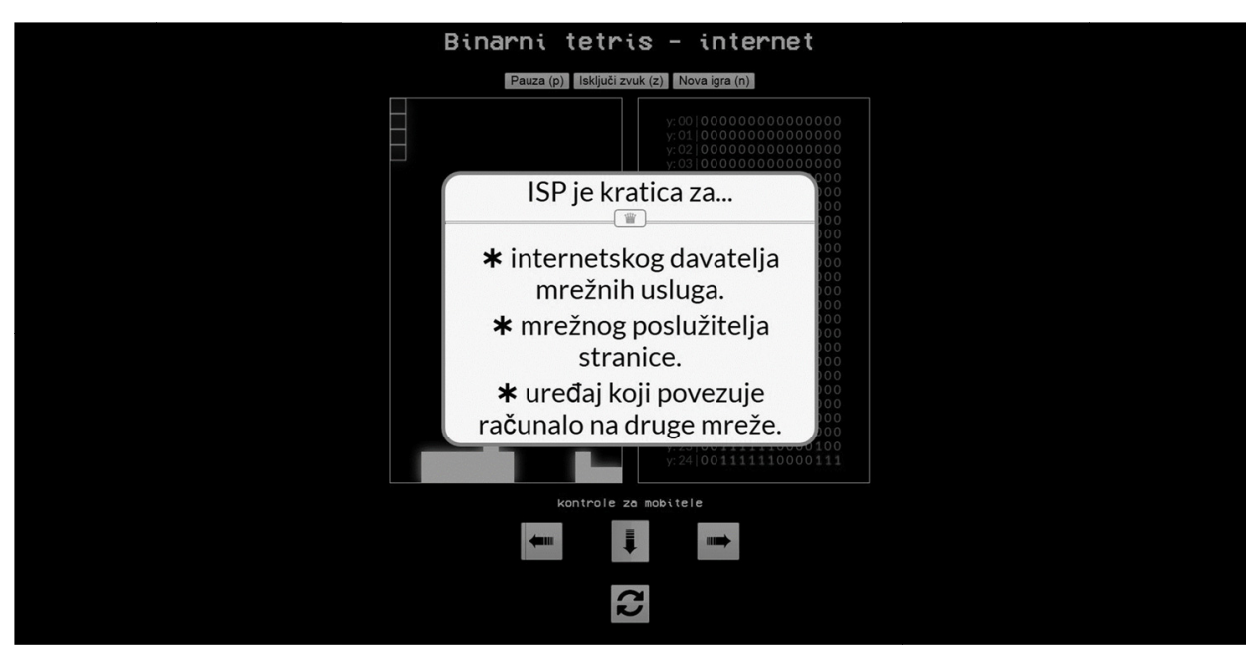

Figure 2. Binary Tetris is a game of Tetris in which questions appear for every completed row

\footnotetext{
${ }^{8}$ Computer games and Other Multimedia Content. 2016. https://informatickeigre.com/ (2. 4.2017)
} 


\section{Archival Games}

In addition to education, some web games can also be used for promoting cultural activities. That is why some museums and libraries create games for promoting their activities and materials. However, there are almost no games for promoting archives and archival activities. That is why archival games are presented on the website of the Croatian Archival Society ${ }^{9}$. The games were created during the development of this site. The purpose of the games is to promote archival practice and materials kept in archives as well as archival pedagogy. There is a memory game with Croatian archives, a jigsaw puzzle where players put together parts to get a picture of an artefact kept in the archive. When a player finishes the puzzle he is given some basic information about the artefact. There is also a typing game which is based on the Archival Dictionary where the player has to type quickly English words and phrases that are used in archival practice. For each word he types correctly he is given its Croatian translation. This game is designed for archivists who want to learn archival terminology and have fun while first two games are designed for anyone interested in archives and are located in the section for archival pedagogy. This content is also in an early stage of development. However, there are plans to expand archival games based on the world map of archives ${ }^{10}$ which is also on this site and which has enough content to create quizzes, crossword puzzles, word search games, and other puzzle games.

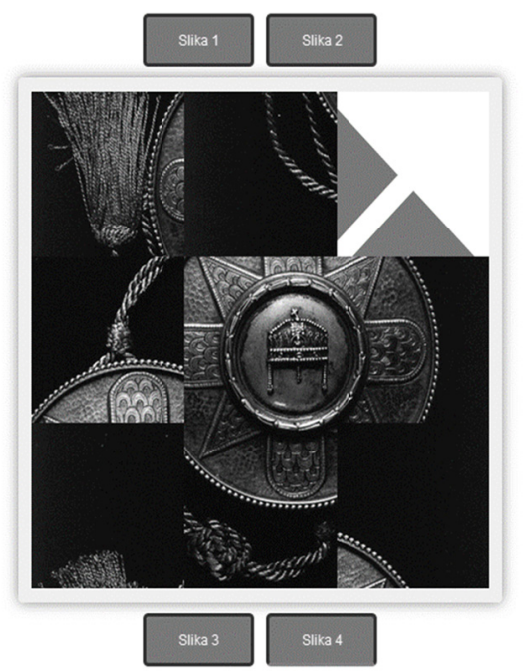

Figure 3. A jigsaw puzzle with archive holdings

\footnotetext{
${ }^{9}$ Archival games. 23.10.2016. http://had-info.hr/arhivisticke-igre (2.4.2017)

${ }^{10}$ The world map of archives. 22.10.2016. http://had-info.hr/arhivi-svijet/ (2.4. 2017)
} 
INFuture2017: Integrating ICT in Society

\section{Technology in Creating Games}

While creating games, the first step is to have a concept for a certain game type. When creating a game that is similar to an already well-known game, the game developer should first check if there is an existing template or code which can be reused free of cost. All of the games presented in this paper were made using free technology accessible through the Internet. All of the games were made using the HTML format that unlike Adobe Flash or Microsoft Silverlight works on all web browsers. Most of the games, e.g. Memory, crossword puzzles, Word Search games, Tic-tac-toe, that do not require keyboard controllers can be played on mobile devices. Some of the games were created by using the H5P web platform ${ }^{11}$. The site allows free creation of many different educational web games through the website GUI and there are a lot of customizing options which allow a more specific design. Many games, such as Croatian spelling quizzes, were made with a quiz game type which allows the creation of multiple type questions, e.g. multiple choice, which can have one or more correct answers, fill in the blanks, drag-n-drop, drag text and mark the words questions. Quiz creators can decide on the number of points for each question and the feedback messages for certain answers. There is also a hint button which can be enabled and options for customizing text messages in buttons and results so quizzes can be made for multiple languages. The solutions and points can be shown immediately after the answer is given or after the whole quiz is completed. There is also a memory game in which some text information is displayed when a pair is matched. This is used for explaining objects in images such as archives in the memory with Croatian archives which was made for the website of the Croatian Archival Society. There is also a flashcard quiz in which an image is displayed and the player must type what he sees on the picture, interactive video where a question is displayed at a certain point in the video, timeline tool for telling stories in a chronological order, image hotspot for marking parts of the image and adding dialog boxes to them which open when the user clicks on a marked part of the image.

The rest of the games were made through available codes and algorithms found on CodePen ${ }^{12}$ website, where web designers and programmers can share and comment each other's work. The codes on that site are protected with MIT license which means that they are free to use and modify without any restrictions but have to include the copyright notice in all copies or other modified versions of the work. The code for certain games such as Tic-tac-toe was modified so that questions appear each time a player makes a move. If a player answers a question correctly, he is allowed to place his mark on the table, if his answer is wrong, he loses a turn. Games such as Flappy Glagolitic and Glagolitic Word

\footnotetext{
${ }^{11}$ H5P. https://h5p.org/ (2.4.2017)

${ }^{12}$ CodePen. http://codepen.io/ (2.4.2017)
} 
Search were modified so that they show Glagolitic fonts and use Croatian words for their learning corpus. They were also graphically modified in the style of the Middle Ages, when Glagolitic letters were used. Memory with Glagolitic letters was created by using Construct $2^{13}$ game engine which allows the creation of the HTML5 game, by using GUI interface, which allows placing graphic resources on canvas (game stage), then placing already finished blocks of code for movement and controls onto the resources. This allows a much easier and faster creation of web and mobile games for developers who don't have strong programming skills. Unfortunately, Construct 2 free version has certain restrictions because it allows publishing games that have only a certain number of events. Other memory games for learning German and Croatian were created using GDevelope $^{14}$, which is very similar to Construct 2 but is open-source, which means that it is completely free to use without any license restriction. Once the tool for creating games is selected and game mechanics programmed, there is a need to create the visual identity for the game by using available graphics and resources. All of the graphical resources used for creating games are license free. They were mostly found on Pixabay ${ }^{15}$ site, which offers thousands of photos and cliparts free for use for any purpose. They especially have a wide range of clipart vector graphics which can be modified to look good on any screen resolutions. Drawings for the game A Day in a Life on the site of Language Games, where a player must drag sentences to a drawing that represents a typical working day was drawn by one of the high school students at a computer science class. The sound clips for Glagolitic memory and snake were created by the musician Ivan Mihaljević ${ }^{16}$ and sound clips for other games were downloaded from Freesound.org site which offers creative-commons licensed sound for musicians and sound lovers. So everything was done free of charge. There are many programs and available codes which can be used free of charge for creating games and other educational content such as timelines with TimeLine $\mathrm{JS}^{17}$, maps with StoryMap JS ${ }^{18}$, and videos with Wirewax ${ }^{19}$.

\footnotetext{
${ }^{13}$ Construct 2. 2011. https://www.scirra.com/construct2 (2.4.2017)

${ }^{14}$ GDevelop. 1.4.2015. http://compilgames.net/ (2.4.2017)

${ }^{15}$ Pixabay. 2010. https://pixabay.com/ (2.4.2017)

${ }^{16}$ Ivan Mihaljević official site. 2017. http://www.ivanmihaljevic.com/ (31.3.2017)

${ }^{17}$ TimeLine JS. 21.9.2016. https://timeline.knightlab.com/ (31.3.2017)

${ }^{18}$ StoryMap JS. 21.11.2016. https://storymap.knightlab.com/ (31.3.2017)

${ }^{19}$ WIREWAX. 31.5.2016. http://www.wirewax.com/ (31.3.2017)
} 


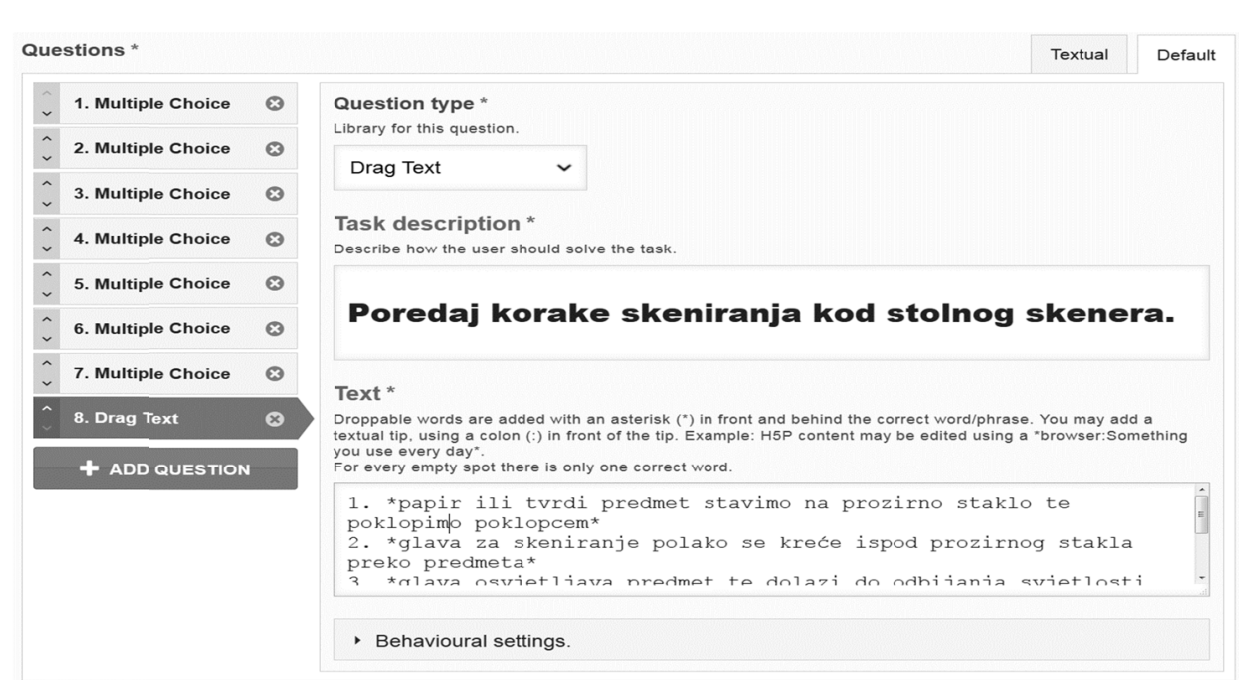

Figure 4. An example of a quiz created in H5P platform

\section{Pilot research}

A short pilot research was conducted in the School for nurses in Vrapče in Zagreb based on the author's use of web games on the site Computer Games and Other Multimedia Content as a means to motivate students to learn and repeat essential facts they learned in Computer Science classes. The games were mostly used at the beginning or the end of a lesson as a way to repeat and practice the previous lessons. An online survey created with KwikiSurveys was given to each of the first and second-year students about the use of games for motivating them. 69 students filled the questionnaire and the results show that $77 \%$ like when the teacher uses games for motivation. $63 \%$ considered that the games helped them learn. However, 51\% students admitted that they did not use the site for repetition before the exam. This means that most of them were not aware of the importance of games for the exam although in the games there were some questions that ended in the exam. Their favorite game (54\%) was Tic-tac-toe with questions followed by Memory where they match computer parts $(22 \%)$. As this survey did not have a large number of examinees, which is at the moment impossible because these games are only used in the first two years and only in one school, it points to the conclusion that most teenagers like when educational games are used in class but are not aware that by playing them they can learn for the test in an efficient way. The results would probably be even better with elementary school children since younger children enjoy games more and Computer Science is not an obligatory subject in Croatian elementary schools so mostly only children who like computers and games enrol in these classes. 
Table 1. Answers to the first three questions

\begin{tabular}{|c|c|c|}
\hline Questions & Yes & No \\
\hline $\begin{array}{l}\text { 1. Do you like it when the teacher uses computer games for } \\
\text { repeating lessons? }\end{array}$ & $53(77 \%)$ & $16(23 \%)$ \\
\hline 2. Did you use the games when you were repeating for the exam? & $34(49 \%)$ & $35(51 \%)$ \\
\hline $\begin{array}{l}\text { 3. Do you think that the games helped you with the learning } \\
\text { process? }\end{array}$ & $39(63 \%)$ & $23(37 \%)$ \\
\hline
\end{tabular}

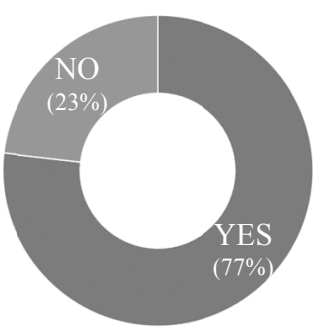

Question 1

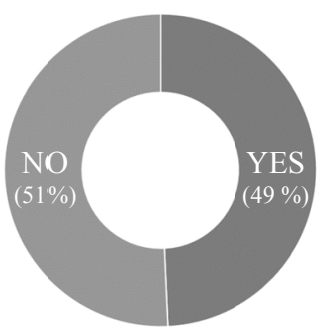

Question 2

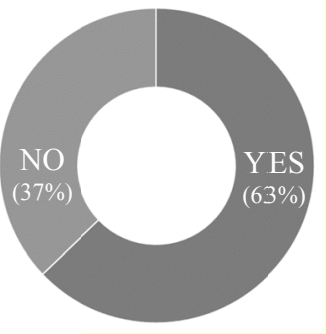

Question 3

Chart 1. Answers to the first three questions

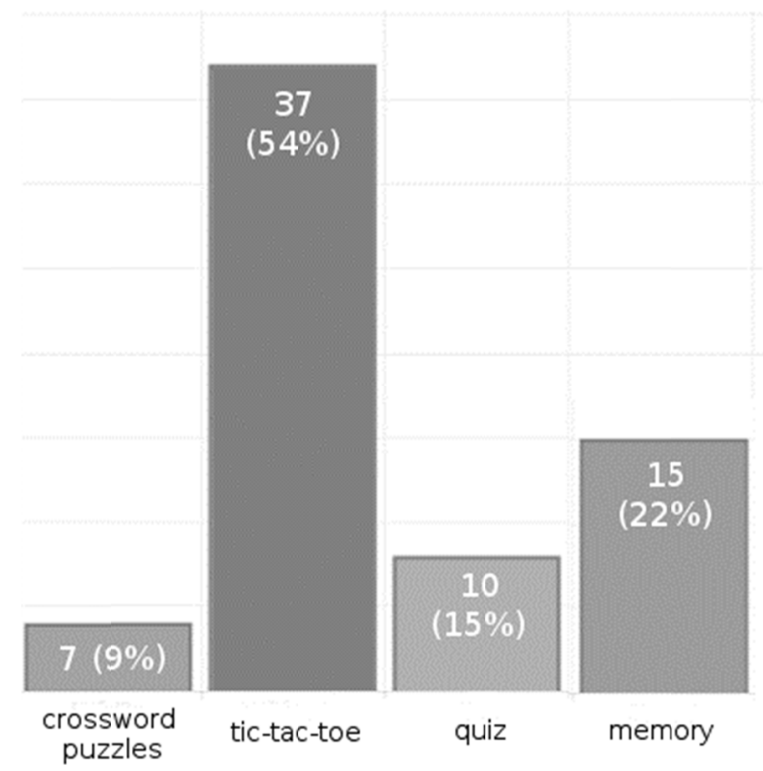

Chart 2. Answers to the question: Which of the game types do you like the most? 
The last question in the questionnaire was which type of a game you would like to see next. This was an open question. Some students wrote names of popular commercial games such as Call of Duty, Grand Theft Auto and FIFA which cannot be used for educational purposes. Many students wrote Tetris, therefore the game Binary Tetris with questions from the field of computer science was created and it became one of the most popular games on this site. Other suggested games that can be made in future are Hangman and Pictionary.

Table 2. Relevant answers to the last question

\begin{tabular}{|l|l|l|}
\hline Which game type would you like to see next? \\
\hline Tetris (7 answers) & Hangman (4 answers) & Pictionary (3 answers) \\
\hline
\end{tabular}

\section{Conclusion}

The idea of an interactive, highly engaging training and education is very old. An old Chinese proverb says: "Tell me, and I'll forget. Show me, and I may remember. Involve me, and I'll understand.” (Popik 2012). While traditional educational methods such as reading, writing, and lecturing are still widely used, the gap between traditional methods and learning through modern interactive multimedia education technology is becoming narrower as technology is entering into more and more classrooms. With that in mind, the future of game-based learning seems to be promising. Even the results of the pilot research show that there is an interest for game based learning among high-school students. However, there is still a growing need to design and develop specific games for learning many different subjects and do research on the influence of gamification and game-based learning in specific classroom and learning situations. For that, a good collaboration between programmers, designers, and teachers has to be established or teachers have to learn how to design and create games for their subjects. Fortunately, technology is becoming more available and much easier to use so in a few years maybe many teachers will be able to create their own game-based learning resources. So in the future, the author hopes to expand his research to other high schools and/or elementary schools.

\section{References}

Ally, M.; Samaka, M. Open Education Resources and Mobile Technology to Narrow the Learning Divide. // The International Review of Research in Open and Distributed Learning. 14 (2013), $2 ; 1-2$

Anderson, P. H.; Lawton, L. Business simulations and cognitive learning: Developments, desires, and future directions. // Simulation \& Gaming. 40 (2009); 193-216

Archival games. 23.10.2016. http://had-info.hr/arhivisticke-igre (2.4.2017.)

Bilić, V.; Gjukić, D.; Kirinić, G. Mogući učinci igranja računalnih igrica i videoigara na djecu i adolescente. // Napredak : časopis za pedagogijsku teoriju i praksu. 151 (2010), 2; 195-213.

Binary Tetris. 13.1.2017. https://informatickeigre.com/1r/binarni-teris-internet/ (2.4. 2017.)

CodePen. http://codepen.io/ (2.4.2017)

Computer games and Other Multimedia Content. 2016. https://informatickeigre.com (2. 4.2017.)

Construct 2. 2011. https://www.scirra.com/construct2 (2.4.2017) 
Croatian dictionary history timeline. 2016. http://jezicneigre.com/hr/povijest-rjecnika/ (2. 4.2017.)

Croatian in School. 2017. http://hrvatski.hr/ (2. 4.2017.)

Croatian language in games. 2017. http://hrvatski.hr/igre/ (2. 4.2017.)

Dovedan, Z.; Seljan, S.; Vučković, K. Multimedia in Foreign Language Learning. // Proceedings of the 25th International Convention MIPRO 2002: MEET + MHS. Rijeka: Liniavera, 2002. $72-75$

EBESCO. A Comprehensive Full-Text Database for Multidisciplinary Research. 24.2.2012. https://www.ebscohost.com/academic/academic-search-complete (29.3.2017)

Garris, R.; Ahlers, R.; Driskell, J. E. Games, motivation, and learning: A research and practice model. // Simulation \& Gaming. 33 (2002); 441-467

Gasston, P. Moderni web: responzivan web dizajn uz HTML5, CSS i JavaScript. Zagreb: Dobar plan, 2013

GDevelop. 1.4.2015. http://compilgames.net/ (2.4.2017.)

Glagolitic games. 2017. https://zci.stin.hr/hr/article/112/osmosmjerka_s_glagoljicom (2. 4.2017.)

Gros, Begoña. Digital Games in Education: The Design of Games-Based Learning Environments. // Journal of Research on Technology in Education. 40 (2007), 1; 31-36

H5P. https://h5p.org/ (2.4.2017.)

Hall, R. Moodle Tip: How to award badges in Moodle based on different levels of performance. 4.8.2015. http://blog.howtomoodle.com/blog/moodle-tip-how-to-award-badges-in-moodlebased-on-different-levels-of-performance (30.3.2017.)

Higgins, M. Five Video Games That Owe Their Success To The Wars Of The Past. 9.1.2017. https://www.warhistoryonline.com/instant-articles/five-video-games-owe-success-warspast.html (30.3.2017.)

Ivan Mihaljević official site. 2017. http://www.ivanmihaljevic.com/ (31.3.2017.)

Language games and multimedia display of language - Facebook page. 2017. https://www facebook.com/jezicne/ (2. 4.2017.)

McFarlane, A.; Sparrowhawk, A.; Heald, Y. Report on the educational use of games. 2002. http://www.teemorg.uk/resources/teem_gamesined_full.pdf (31.3.2017.)

Meihua, Q.; Clark, Karen R. Game-based Learning and 21st century skills: A review of recent research. // Computers in Human Behavior. 63 (2016), 50-58

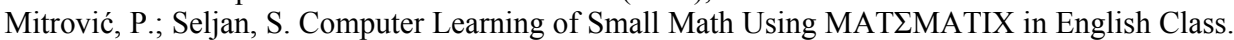
// Proceedings of the 31st International Convention on Information and Communication Technology, Electronics and Microelectronics MIPRO. Opatija: MIPRO, 2008. 248-252

Orlando, K. Superhot review: Time is on my side. 25.2.2016. https://arstechnica.com/gaming/ 2016/02/superhot-review-time-is-on-my-side/ (24.3.2017.)

Pixabay. 2010. https://pixabay.com/ (2.4.2017.)

Popik, B. "Tell me and I forget; teach me and I may remember; involve me and I will learn".19.12.2012.

http://www.barrypopik.com/index.php/new_york_city/entry/tell_me_and_i_forget_teach_me and_i_may_remember_involve_me_and_i_will_lear/ (31.3.2017.)

Slavorum. Croats developed a new game! Meet "flappy" glagoljica!. 17.11.2016. http://www. slavorum.org/croats-developed-a-new-game-meet-flappy-glagoljica/ (2. 4.2017.)

Spencer. Ubisoft to teach DS owners French and Spanish?. 15.5.2007. http://www.siliconera. com/2007/05/15/ubisoft-to-teach-ds-owners-french-and-spanish/ (30.3.2017.)

StoryMap JS. 21.11.2016. https://storymap.knightlab.com/ (31.3.2017.)

The world map of archives. 22.10.2016. http://had-info.hr/arhivi-svijet/ ( 2.4. 2017.)

TimeLine JS. 21.9.2016. https://timeline.knightlab.com/ (31.3.2017.)

Trybus, J. Game-Based Learning: What it is, Why it Works, and Where it's Going. 14.1.2009. http://www.newmedia.org/game-based-learning--what-it-is-why-it-works-and-where-itsgoing.html (2.4.2017.) 
INFuture2017: Integrating ICT in Society

Williams, R. What is Flappy Bird? The game taking the App Store by storm. 29.1.2014. http://www.telegraph.co.uk/technology/news/10604366/What-is-Flappy-Bird-The-gametaking-the-App-Store-by-storm.html (24.3.2017)

Wilson, K. A.; Bedwell, W. L.; Lazzara, E. H.; Salas, E.; Burke, C. S.; Estock, J. L.; Conkey, C. Relationships between game attributes and learning outcomes. // Simulation \& Gaming. 40 (2009); 217-266.

WIREWAX. 31.5.2016. http://www.wirewax.com/ (31.3.2017.) 